\title{
The Effect of Annealing Atmosphere on the Evolution Behavior of Inhibitors in Thin-Gauge Grain-Oriented Silicon Steel
}

\author{
Fuyao Yang ${ }^{1,2}$, Chengxu $\mathrm{He}^{2}$, Li Meng ${ }^{3, *}$, Guang $\mathrm{Ma}^{2}$, Xin $\mathrm{Chen}^{2}$, Pengfei Hou ${ }^{4}$, Wenkang Zhang ${ }^{4}$ \\ and Weimin $\mathrm{Mao}^{1}$ \\ ${ }^{1}$ School of Materials Science and Engineering; University of Science and Technology Beijing, Beijing 100083, China \\ ${ }^{2}$ Department of Electrical Engineering New Materials, Global Energy Interconnection research institute, Beijing 102211, China \\ ${ }^{3}$ Central Iron and Steel Research Institute, Beijing 100081, China \\ ${ }^{4}$ Technical Center, Taiyuan Iron and Steel (Group) Co., Ltd, Taiyuan 030003, China
}

In this paper, $0.18 \mathrm{~mm}$ thin-gauge S-type steels with $\mathrm{MnS}$ and $\mathrm{N}$-type steels with $\mathrm{AlN}$ as main inhibitors, respectively, were fabricated using three different final annealing systems. Moreover, the evolution behavior of the MnS and AlN [(Al, Si)N] particles and grain orientation were investigated. Number density and mean diameter of second-phase particles were statistically determined by field-emission scanning electron microscopy. Results indicated that evolution of $\mathrm{MnS}$ and AlN would be suppressed with increased $\mathrm{N}_{2}$ content during annealing. The onset ripening temperature of $\mathrm{MnS}$ was lower than that of AlN particle, which caused secondary recrystallization in the S-type samples at lower temperature compared with that of the N-type samples. Moreover, for the N-type steel fabricated by nitriding method, the effective inhibitor was (Al, Si)N formed by the decomposition of (Al, Mn, Si)N. The decomposition of (Al, Mn, Si)N particles and coarsening of (Al, Si)N inhibitors were strongly inhibited and delayed with increased $\mathrm{N}_{2}$ content in annealing atmosphere. In conclusion, $\mathrm{N}_{2} / \mathrm{H}_{2}$ ratio of annealing atmosphere could be an effective control parameter to enhance the inhibition ability and delay secondary recrystallization onset in forming sharp Goss texture. [doi:10.2320/matertrans.M2017114]

(Received April 28, 2017; Accepted August 28, 2017; Published September 29, 2017)

Keywords: thin-gauge cold-rolled grain-oriented silicon steel, annealing atmosphere, inhibitor, MnS, AlN

\section{Introduction}

Cold-rolled grain-oriented silicon steel widely used in electric and electronic industry is the core material that affects the energy consumption of a transformer. Decreasing the thickness of the steel can significantly reduce eddy current loss and promote the energy saving of transformers. Thus, this process has become a main trend in the development of advance technology on steel fabrication. However, compared with thick-gauge silicon steel, production of thin products requires heavy cold-rolling deformation which will lead to significant reduction in proportion of Goss texture component ${ }^{1)}$. Moreover, this process might increase the sensitivity of grain growth due to the change in atmosphere during final annealing. Simultaneously, the ripening rate of inhibitors in thin-gauge silicon steel is also hastened such that the pinning effect of particles in the surface layer of matrix will be easily invalidated, hampering the formation of sharp Goss texture ${ }^{2}$. Therefore, controlling the ripening rate of inhibitors in thin-gauge grain-oriented silicon steel during preparation is the key to obtain sharp Goss texture.

The inhibitors of grain-oriented silicon steel mainly include $\mathrm{MnS}, \mathrm{AlN}$, and $\mathrm{Cu}_{2} \mathrm{~S}$. Numerous studies on 0.23-0.30$\mathrm{mm}$ thick grain-oriented silicon steels ${ }^{3-9)}$ have focused on the solution, precipitation, and coarsening of $\mathrm{MnS}$ and $\mathrm{AlN}$ particles. MnS particles are likely to precipitate during hot rolling ${ }^{5,10)}$ and tend to nucleate and precipitate at the dislocation when the deforming temperature is low, but precipitate at grain boundaries ${ }^{11)}$. After partial dissolution in the matrix during cold-rolling deformation ${ }^{12-15)}$, MnS particles will precipitate completely by decarburizing annealing at $850^{\circ} \mathrm{C}^{11,15)}$ and start to coarsen at $875^{\circ} \mathrm{C}$ during final anneal-

*Corresponding author, E-mail: li_meng@126.com ing ${ }^{16)}$. The pinning force of MnS is weaker and tends to disappear earlier than that of $\mathrm{AlN}^{17,18)}$, hindering the abnormal growth of Goss grains to have enough time to inoculate to obtain a sharp Goss texture. Therefore, a single inhibitor by $\mathrm{MnS}$ is usually used to prepare common grain-oriented silicon steel. AlN particle is usually used to produce high-magnetic induction oriented silicon steel using inherent or acquired inhibitor method $^{19,20)}$ as its strong inhibition ${ }^{21,22)}$. In the inherent inhibitor method, the AlN particle is mainly derived from the precipitation in the normalized stage $\mathrm{e}^{7)}$. Meanwhile, under the $25 \% \mathrm{H}_{2}+75 \% \mathrm{~N}_{2}$ (volume fraction, vol\%) annealing atmospheric condition in the final annealing process, AlN particles start to ripen at $900^{\circ} \mathrm{C}$ and lose inhibition ability below $980^{\circ} \mathrm{C}^{23)}$. For the acquired inhibitor method, due to the initial alloy composition, the formation of large amount of AlN particles mainly depends on the decomposition and transformation of $\mathrm{Si}_{3} \mathrm{~N}_{4}$ formed by nitriding treatment as temperature reaches more than $700^{\circ} \mathrm{C}$ in the final annealing process ${ }^{24,25)}$. In addition, the ripening temperature of AlN particles is higher that of the inherent inhibitor method and causes the temperature of secondary recrystallization to be higher than $1000^{\circ} \mathrm{C}^{26)}$.

The annealing atmosphere, annealing temperature, and inhibitor type are the key factors in the inhibitor ripening behavior and in the characteristics of annealing microstructure and texture. In particular, the ratio of $\mathrm{N}_{2}$ and $\mathrm{H}_{2}$ in the annealing atmosphere is the main parameter that influences the precipitation and coarsening behavior of inhibitors. The evolution behavior of MnS under different annealing atmospheres during the final annealing process is rarely reported. For AlN inhibitors, AlN precipitation is inhibited in 0.23 -and $0.30-\mathrm{mm}$ thick oriented silicon steels, and secondary recrystallization temperature increases at high $\mathrm{N}_{2}$ partial pressure $^{19)}$. By contrast, the secondary recrystallization tempera- 
ture would be lower and AIN is more likely to decompose at a lower temperature as the $\mathrm{N}_{2}$ partial pressure becomes lower ${ }^{23)}$. A study on the evolution behavior of AlN particles under different atmosphere conditions showed that more $\mathrm{N}$ atoms will be lost from the matrix, and AlN particles are more likely to coarsen at $920^{\circ} \mathrm{C}$ with prolonged treatment at lower $\mathrm{N}_{2}$ partial pressure ${ }^{27}$. These studies on atmospheric factors are based on $0.23-0.30-\mathrm{mm}$ thick oriented silicon steel. Thickness reduction will make the steel more sensitive to atmospheric changes during final annealing, and the inhibitors are more likely to ripen. Consequently, the evolution behavior of inhibitors in thin-gauge grain-oriented silicon steel in the final annealing will differ from that of the thickgauge grain-oriented silicon steel. Accordingly, the evolution behavior of $\mathrm{MnS}$ and AlN inhibitors in $0.18-\mathrm{mm}$ or thinner grain-oriented silicon steel under different atmospheres cannot be determined based on existing studies. Moreover, the ripening of two kinds of particles under different annealing atmospheres and its effect on annealing microstructure and texture remain unclear.

In our previous work, the effects of nitrogen content in the annealing atmosphere on the behavior of inhibitors of grain-oriented silicon steel with different thickness $(0.23$ and $0.18 \mathrm{~mm}$ ) was investigated ${ }^{28)}$. In this paper, the evolution behavior of $\mathrm{MnS}$ and AlN particles in $0.18 \mathrm{~mm}$ specimens under different annealing atmospheres and soaking times was systematically analyzed. In addition, the effect of evolution behavior of particles on the formation of Goss texture was evaluated. This study can provide a theoretical basis to improve the control of the final annealing atmosphere for preparing thin-gauge silicon steel with different inhibitors.

\section{Experimental Procedure}

Two components of normalized plates with $2.20 \mathrm{~mm}$ thickness were used as raw materials. The plate with $\mathrm{MnS}$ as the main inhibitor was labeled as S-type, and the plate with AlN as the main inhibitor was labeled as N-Type. The two kinds of plates were cold-rolled to $0.18 \mathrm{~mm}$ and then treated by decarburizing annealing at $850^{\circ} \mathrm{C}$. N-type samples after decarburizing annealing underwent nitriding treatment at $750^{\circ} \mathrm{C}$. Then, the samples were heat-treated at $850^{\circ} \mathrm{C}$ for $2 \mathrm{~h}$ to ensure the complete decomposition of $\mathrm{Si}_{3} \mathrm{~N}_{4}$ which was formed in the surface layer after nitriding ${ }^{24,25)}$ and to diffuse the $\mathrm{N}$ atoms from the surface to the central layer to dissolve into the matrix or react with $\mathrm{Al}$ to form nitrides ${ }^{29,30)}$. The compositions of the treated N-type samples and annealed S-Type samples are shown in Table 1. Then, the effect of atmospheric nitrogen was studied by annealing the samples under $10 \% \mathrm{H}_{2}+90 \% \mathrm{~N}_{2}, 50 \% \mathrm{H}_{2}+50 \% \mathrm{~N}_{2}$, and $90 \% \mathrm{H}_{2}+10 \% \mathrm{~N}_{2}$ atmosphere. The S-type samples were annealed at $950^{\circ} \mathrm{C}$, while the $\mathrm{N}$-type samples were annealed at $950^{\circ} \mathrm{C}$ (labeled as $\mathrm{N}$-type ${ }_{1}$ ) and $1000^{\circ} \mathrm{C}$ (labeled as $\mathrm{N}$-type ${ }_{2}$ ). The heating

Table 1 Nominal composition of samples (mass\%).

\begin{tabular}{lllllll}
\hline & $\mathrm{C}$ & $\mathrm{Si}$ & $\mathrm{Mn}$ & $\mathrm{S}$ & $\mathrm{Al}$ & $\mathrm{N}$ \\
\hline S-Type & $<0.003$ & 3.0 & 0.12 & 0.018 & 0.016 & 0.006 \\
N-Type & $<0.003$ & 3.0 & 0.05 & 0.005 & 0.03 & 0.033 \\
\hline
\end{tabular}

rate was $8^{\circ} \mathrm{C} / \mathrm{s}$. Both S-type and N-type samples were taken after certain periods $(1,3$, and $5 \mathrm{~h}$ ) by interrupting the evolution of precipitate with water quenching. The specific process is shown in Fig. 1. The surfaces of the interrupted samples were ground in a rolling plane and a cross-sectional plane, followed by polishing and erosion treatment. Then, the microstructure was observed by BX51m Olympus metallurgical microscope, and orientation was analyzed by Oxford HKL Channel5 electron backscatter diffraction in the cross section. In addition, the particles were observed by scanning electron microscopy (SEM) (ZEISS-ULTRA55) and transmission electron microscopy (TEM) (G2 F30 Tecnai) with energy-dispersive spectroscopy (EDS) in the rolling surface.

\section{Results and Discussions}

\subsection{Microstructure and grain orientation characteristics}

The S-type samples completely underwent secondary recrystallization under $90 \% \mathrm{H}_{2}+10 \% \mathrm{~N}_{2}$ atmosphere at $950^{\circ} \mathrm{C}$ for $1 \mathrm{~h}$, and the $\{200\}$ pole figures show that deviated Goss orientation was the main texture component, as shown in Fig. 2. The samples under $10 \% \mathrm{H}_{2}+90 \% \mathrm{~N}_{2}$ atmosphere completely underwent secondary recrystallization after $3 \mathrm{~h}$ of soaking time, and the deviation angle from Goss orientation was smaller than that under $90 \% \mathrm{H}_{2}+10 \% \mathrm{~N}_{2}$. The samples annealed under $50 \% \mathrm{H}_{2}+50 \% \mathrm{~N}_{2}$ atmosphere had the longest secondary recrystallization time. These samples started to undergo secondary recrystallization after $3 \mathrm{~h}$ of soaking time and completely formed sharp Goss texture at $5 \mathrm{~h}$.

No significant change in the grain size was found in $\mathrm{N}$-type specimens soaked at $950^{\circ} \mathrm{C}$ or $1000^{\circ} \mathrm{C}$ for $5 \mathrm{~h}$, and these samples did not undergo secondary recrystallization under any annealing atmosphere, as shown in Fig. 3.

\subsection{Observation of second-phase particles}

Data were collected from 100 micrographs in the precipitation region to enhance the accuracy of the statistical data. Figures 4 and 5 show the average diameter and number den-

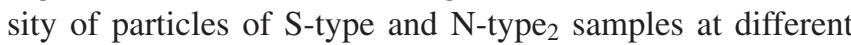
annealing atmospheres and times. The number density and average diameter of particles changed obviously with increase in soaking time, and the variation trends of the parti-

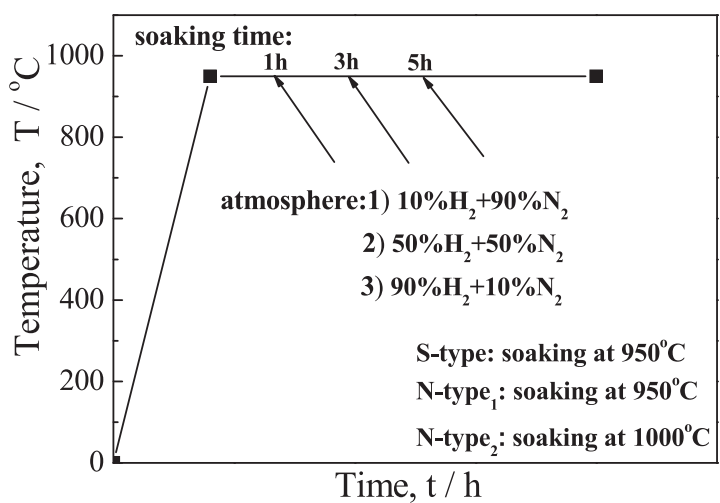

Fig. 1 Annealing process associated with Atmosphere-Temperature-Time 

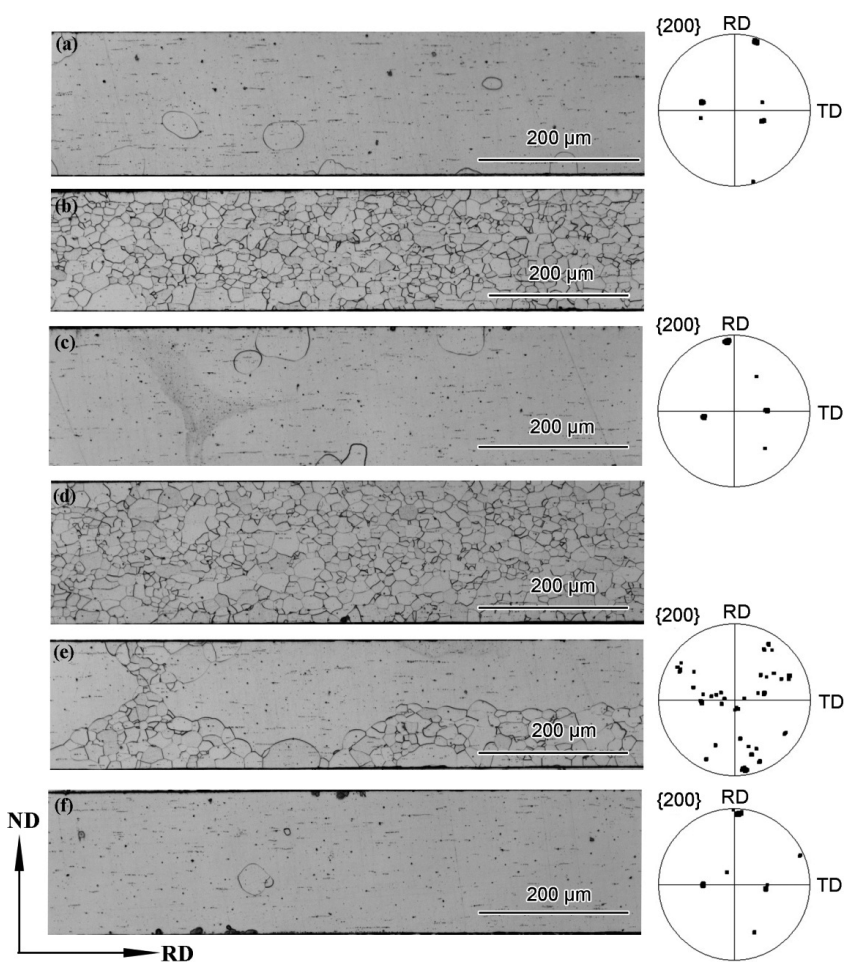

$\{200\}$ RD

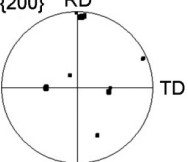

Fig. 2 Microstructure and $\{200\}$ pole figures of S-Type samples under different soaking time and annealing atmosphere at $950{ }^{\circ} \mathrm{C}$ (a) $10 \%$ $\mathrm{N}_{2}+90 \% \mathrm{H}_{2}-1 \mathrm{~h}$, (b) $90 \% \mathrm{~N}_{2}+10 \% \mathrm{H}_{2}-1 \mathrm{~h}$, (c) $90 \% \mathrm{~N}_{2}+10 \% \mathrm{H}_{2}-3 \mathrm{~h}$, (d) $50 \% \mathrm{~N}_{2}+50 \% \mathrm{H}_{2}-3 \mathrm{~h}$, (e) $50 \% \mathrm{~N}_{2}+50 \% \mathrm{H}_{2}-3 \mathrm{~h}$, (f) $50 \% \mathrm{~N}_{2}+50 \% \mathrm{H}_{2}-5 \mathrm{~h}$
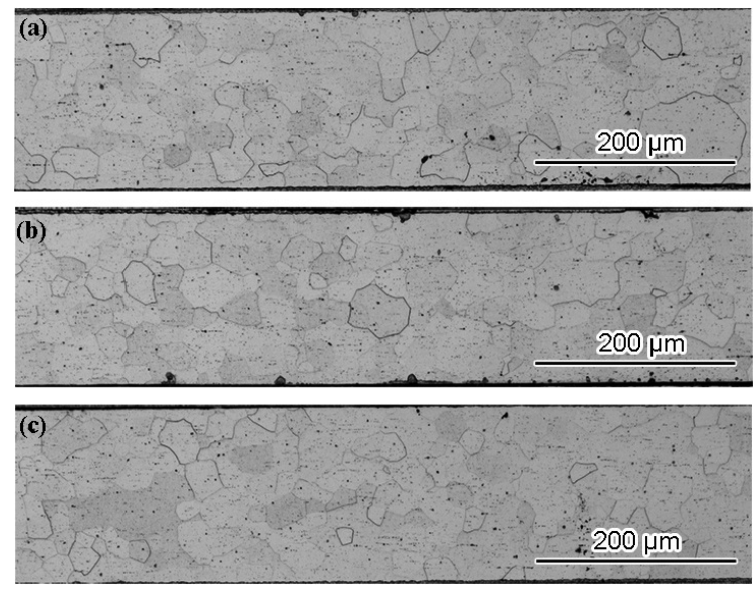

Fig. 3 Microstructure of N-Type samples under different annealing conditions (a) $950^{\circ} \mathrm{C}-10 \% \mathrm{~N}_{2}+90 \% \mathrm{H}_{2}-5 \mathrm{~h}$, (b) $1000^{\circ} \mathrm{C}-10 \% \mathrm{~N}_{2}+90 \% \mathrm{H}_{2}-5 \mathrm{~h}$, (c) $1000^{\circ} \mathrm{C}-90 \% \mathrm{~N}_{2}+10 \% \mathrm{H}_{2}-5 \mathrm{~h}$.

cle states of the two types of samples differed under distinct atmosphere conditions. In this experiment, $\mathrm{MnS}$ precipitated almost completely in the early stages. Thus, MnS particles mainly coarsen when soaked at $950^{\circ} \mathrm{C}$, and the coarsening rate will be affected by changing the annealing atmosphere. Referring to Fig. 4, prolonged soaking time for the S-type samples resulted in the downward trend for the number density of particles, which varied in the range of $1-8 / \mu \mathrm{m}^{2}$, but increasing trend for the particle size, which changed from $30 \mathrm{~nm}$ to $100 \mathrm{~nm}$. The maximum number density of particles and minimum average diameter were observed under
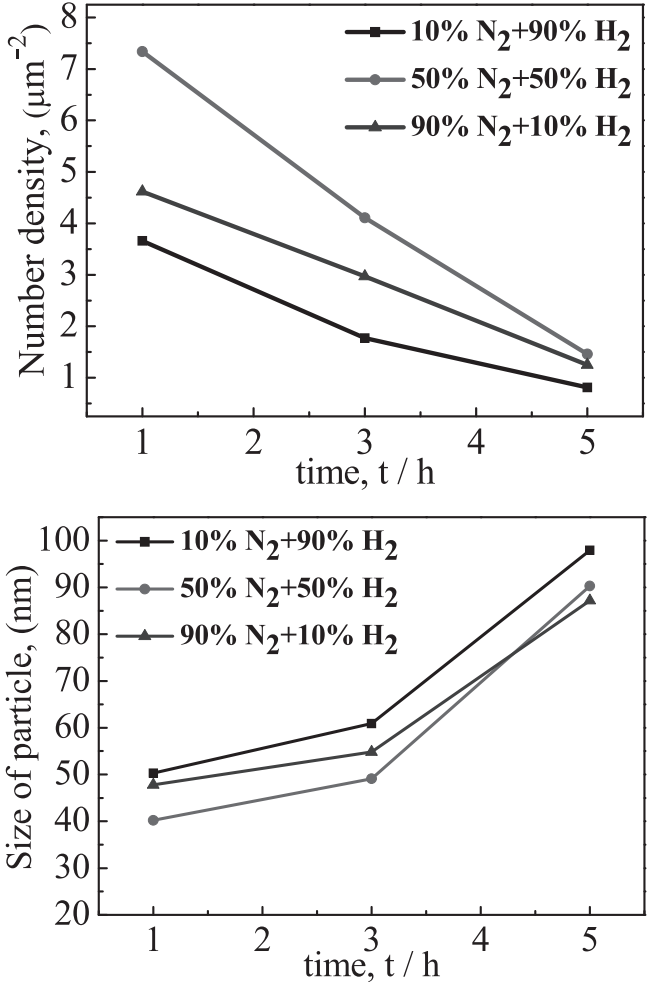

Fig. 4 Number density and mean diameter of the particles of the S-Type samples at different atmospheres and time at $950^{\circ} \mathrm{C}$.
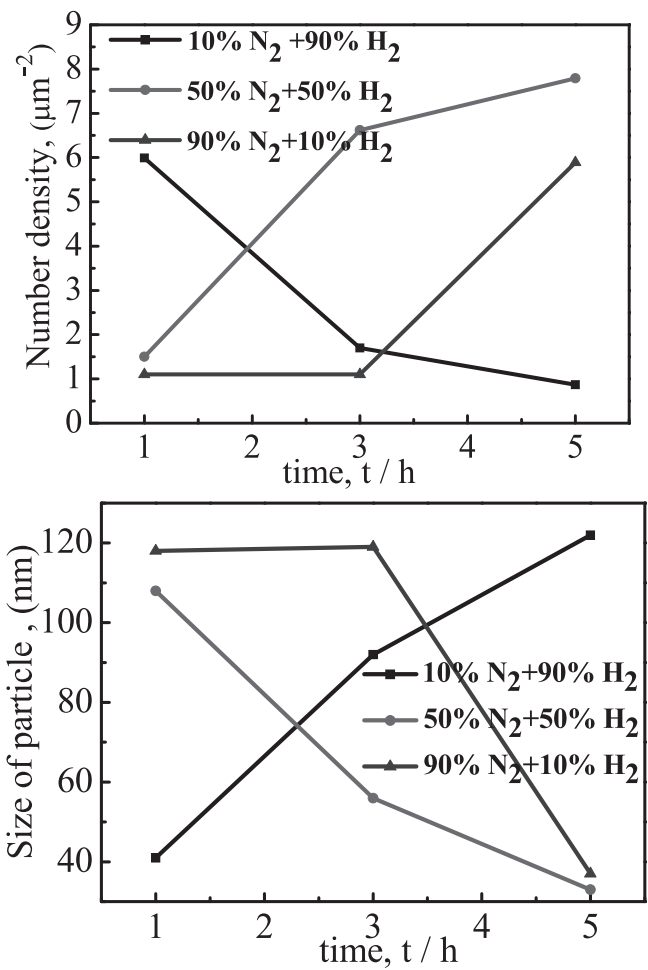

Fig. 5 Number density and mean diameter of the particles of the N-Type 2 samples at different atmospheres and time at $1000^{\circ} \mathrm{C}$.

$50 \% \mathrm{H}_{2}+50 \% \mathrm{~N}_{2}$ atmosphere, compared with those under the other two atmospheric conditions. For N-type 2 samples, the number density of particles varied in the range of $1-9 / \mu \mathrm{m}^{2}$, and particle size changed from $30 \mathrm{~nm}$ to $120 \mathrm{~nm}$. Moreover, 
the variation trend of these samples significantly differed from that of the S-type samples, as shown in Fig. 5.

No obvious changes in the microstructure and inhibitor state were observed for $\mathrm{N}$-type ${ }_{1}$ samples soaked at $950^{\circ} \mathrm{C}$. The average particle size $(115 \mathrm{~nm})$ and number density of particles $\left(1.2 / \mu \mathrm{m}^{2}\right)$ were almost unchanged under different conditions, indicating the very slow ripening rate of $\mathrm{AlN}$ inhibitors in $0.18 \mathrm{~mm}$ specimens. Compared with reported results ${ }^{27)}$, increasing the thickness of the oriented silicon steel may result in higher ripening temperature of AlN.

\subsection{Comparative analysis of particle evolution behavior}

Figure 6 shows the morphologies and chemical compositions of particles in S-type samples under different atmospheric conditions and soaked at $950^{\circ} \mathrm{C}$ for $3 \mathrm{~h}$. Under
$10 \% \mathrm{~N}_{2}+90 \% \mathrm{H}_{2}$ atmosphere, the particles were circular and elliptical, and these particles mainly consisted of $\mathrm{MnS}$ with size of approximately $100-500 \mathrm{~nm}$ with reference to Figs. 6(a) and (b). Under $50 \% \mathrm{~N}_{2}+50 \% \mathrm{H}_{2}$ atmosphere, the particles not only included circular composite particles formed with (Al, Si)N and $\mathrm{MnS}$, but also a certain number of rectangular $(\mathrm{Al}, \mathrm{Si}) \mathrm{N}$ particles with reference to Figs. 6(c) and (d). The chemical compositions of composite particles are corresponding to the large plot and the chemical compositions of fine (Al, $\mathrm{Si}$ ) $\mathrm{N}$ particles are corresponding to the small plot in Fig. 6(d). Under $90 \% \mathrm{~N}_{2}+10 \% \mathrm{H}_{2}$ atmosphere, the particles were mainly $\mathrm{MnS}$ of small size, only a few big-sized $\mathrm{MnS}$ was found with reference to Figs. 6(e) and (f). Nitride particles were not observed under $10 \% \mathrm{~N}_{2}+90 \% \mathrm{H}_{2}$ or $90 \% \mathrm{~N}_{2}+10 \% \mathrm{H}_{2}$ atmosphere, whereas a
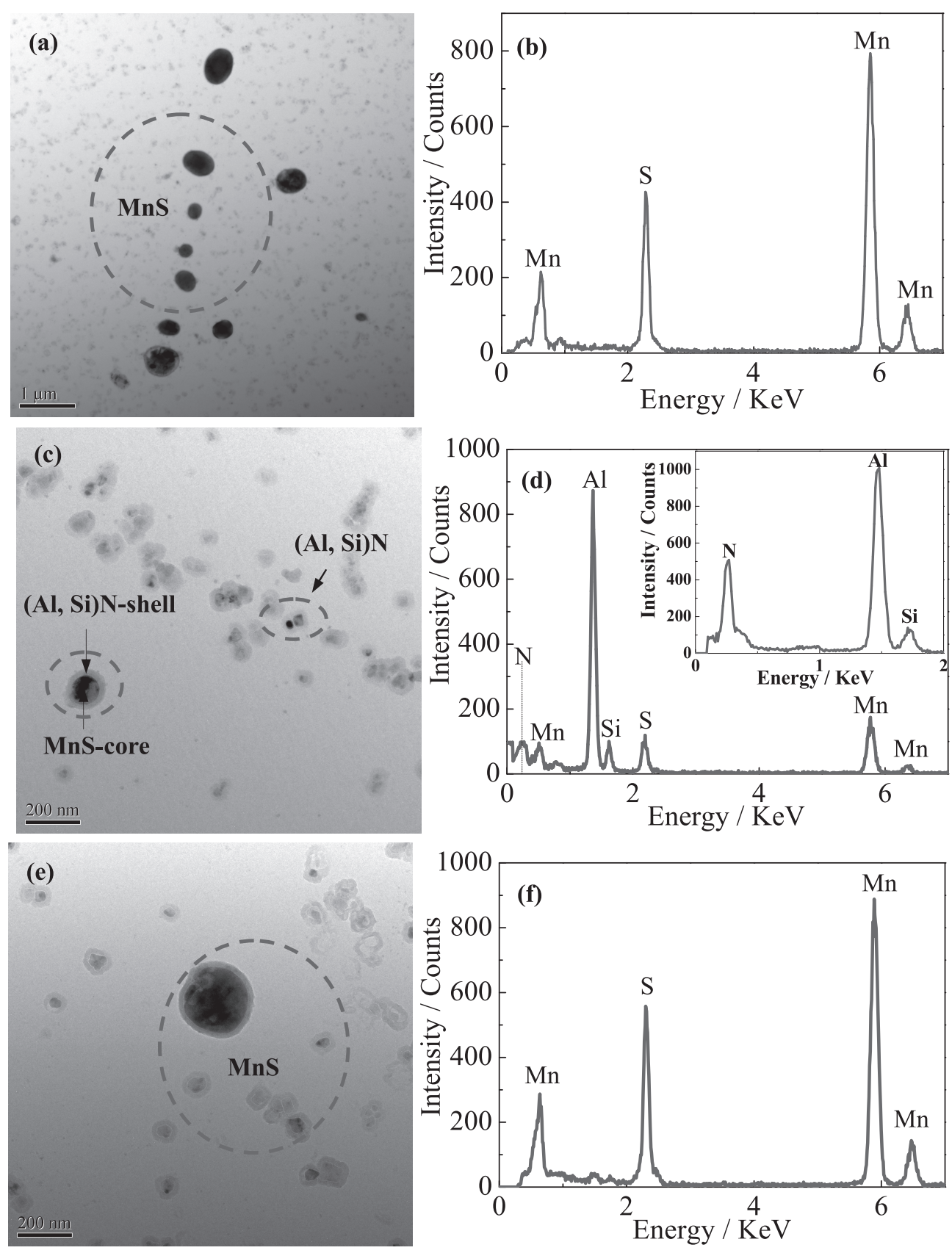

Fig. 6 Morphologies and chemical compositions of particles in S-Type samples soaking at $950^{\circ} \mathrm{C}$ for $3 \mathrm{~h}$ (a) $10 \% \mathrm{~N}_{2}+90 \% \mathrm{H}_{2}$, (b) EDS profile for MnS particle in Fig. (a), (c) $50 \% \mathrm{~N}_{2}+50 \% \mathrm{H}_{2}$, (d) EDS profiles for composite particle in Fig. (c), (e) $90 \% \mathrm{~N}_{2}+10 \% \mathrm{H}_{2}$, (f) EDS profile for MnS in Fig. (e). 
large number of nitride particles were observed under $50 \% \mathrm{~N}_{2}+50 \% \mathrm{H}_{2}$ atmosphere. These results indicate that nitrides can be formed by nitriding under $50 \% \mathrm{~N}_{2}+50 \% \mathrm{H}_{2}$ atmosphere. The samples were heated very fast, and they reached $950^{\circ} \mathrm{C}$ in a very short period of time. The state of the particles did not change during the heating process. Figures 2-4 show that the particle coarsening rate was fastest under $10 \% \mathrm{~N}_{2}+90 \% \mathrm{H}_{2}$ atmosphere because of the high $\mathrm{H}_{2}$ content, and the density was lower and particle size was bigger than those under the other two atmospheres. Moreover, the $\mathrm{S}$ atoms in the silicon steels can be easily lost, decreasing the secondary recrystallization temperature and time $^{31)}$. Thus, the samples underwent secondary recrystallization first and formed deviated Goss texture at $1 \mathrm{~h}$ under $10 \% \mathrm{~N}_{2}+90 \% \mathrm{H}_{2}$ atmosphere. Increasing soaking time led to the gradual coarsening of the particles such that the number density of particles continued decreased, and particle size gradually increased. The coarsening of $\mathrm{MnS}$ particles was strongly inhibited under $90 \% \mathrm{~N}_{2}+10 \% \mathrm{H}_{2}$ atmosphere. During the early soaking stage, the average number density of particles was higher than that under $10 \% \mathrm{~N}_{2}+90 \% \mathrm{H}_{2}$ atmosphere with reference to Fig. 4. This characteristic will also lead to a slowdown in the failure of the pinning force, delaying the occurrence of secondary recrystallization. Coarsening of the MnS particles resulted in the complete secondary recrystallization of the samples within $3 \mathrm{~h}$ of soaking time. By contrast, higher density and finer particle size were observed in the initial soaking stage under $50 \% \mathrm{~N}_{2}+50 \% \mathrm{H}_{2}$ atmosphere because of the formation of fine nitride particles. This phenomenon might cause a stronger pinning force and prolonged time for secondary recrystallization than that under $90 \% \mathrm{~N}_{2}+10 \% \mathrm{H}_{2}$ atmosphere. With prolonged soaking time, the coarsening of particles was dominant, and the pinning force was weakened. This process resulted in the secondary recrystallization at $3 \mathrm{~h}$, which was completed at $5 \mathrm{~h}$, and a sharp Goss texture was formed.

Figure 7 shows the morphology and chemical composition of the N-Type ${ }_{1}$ and N-Type 2 samples after soaking at $950^{\circ} \mathrm{C}$ for $5 \mathrm{~h}$ and $1000^{\circ} \mathrm{C}$ for $1 \mathrm{~h}$, respectively, under $10 \% \mathrm{~N}_{2}+90 \% \mathrm{H}_{2}$ atmosphere.

No obvious changes were found in the number density and size of particles in N-type ${ }_{1}$ samples soaked at $950^{\circ} \mathrm{C}$. Thus, the state of the particles in $\mathrm{N}^{-T y p e}{ }_{1}$ samples at $950^{\circ} \mathrm{C}$ during insulation stage did not change significantly under this atmospheric condition and may not change in all atmospheres. Moreover, the particles were mainly coarse (Al, $\mathrm{Mn}, \mathrm{Si}) \mathrm{N}$ with reference to Figs. 7(a) and (b). By contrast, soaking at $1000^{\circ} \mathrm{C}$ for $1 \mathrm{~h},(\mathrm{Al}, \mathrm{Mn}, \mathrm{Si}) \mathrm{N}$ in N-type speci- $^{-}$ mens under $10 \% \mathrm{~N}_{2}+90 \% \mathrm{H}_{2}$ atmosphere were not observed but square $(\mathrm{Al}, \mathrm{Si}) \mathrm{N}$ was found. Meanwhile, according to the change in the number density in Fig. 5, the coarse (Al, $\mathrm{Mn}, \mathrm{Si}) \mathrm{N}$ gradually transformed into $(\mathrm{Al}, \mathrm{Si}) \mathrm{N}$ particles with reference to Figs. 7(c) and (d). Compared with the change in the number density and particle size in Fig. 5 under $10 \% \mathrm{~N}_{2}+90 \% \mathrm{H}_{2}$ atmosphere with low nitrogen, the decomposition and transformation could not be suppressed, and a large number of fine ( $\mathrm{Al}, \mathrm{Si}) \mathrm{N}$ nitrides could be formed by the decomposition of $(\mathrm{Al}, \mathrm{Mn}, \mathrm{Si}) \mathrm{N}$ in $1 \mathrm{~h}$. These
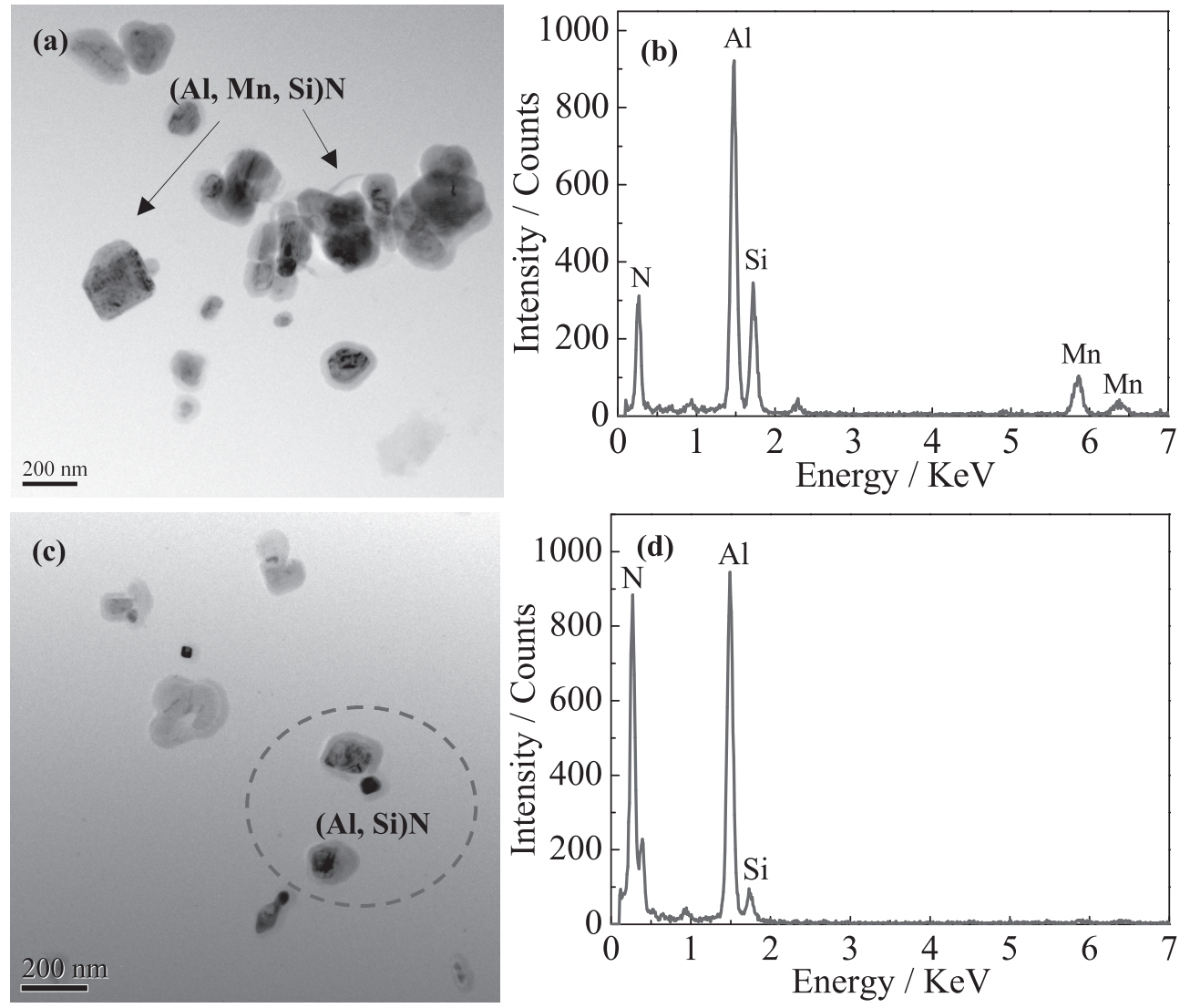

Fig. 7 Morphologies and EDS profiles of particles in N-Type samples (a) N-Type ${ }_{1}$ sample: $10 \% \mathrm{~N}_{2}+90 \% \mathrm{H}_{2}-950{ }^{\circ} \mathrm{C}$ soaking for 5 h, (b) EDS profile for (Al, Si, Mn)N particle in Fig. (a), (c) N-Type 2 sample: $10 \% \mathrm{~N}_{2}+90 \% \mathrm{H}_{2}-1000^{\circ} \mathrm{C}$ soaking for $1 \mathrm{~h}$, (d) EDS profile for (Al, Si)N particle in Fig. (c). 
processes led to higher number density and smaller particle size compared with those under the two other atmospheres. Prolonged holding time resulted in the rapid coarsening of particles similar to the particles in the S-type samples. Under $50 \% \mathrm{~N}_{2}+50 \% \mathrm{H}_{2}$ and $90 \% \mathrm{~N}_{2}+10 \% \mathrm{H}_{2}$ atmosphere, the decomposition of (Al, Mn, Si)N in the matrix was inhibited in the early soaking stage. Prolonged soaking time resulted in the formation of a large number of fine $(\mathrm{Al}, \mathrm{Si}) \mathrm{N}$ nitrides in the later period of heat preservation. This phenomenon led to increased overall number density and gradually decreased average size of particles. Although the particle state changed obviously after soaking at $1000^{\circ} \mathrm{C}$, secondary recrystallization did not occur at this temperature within $5 \mathrm{~h}$.

Comparison of the S-type and N-type samples showed that the atmosphere significantly affected the particle coarsening behavior. For S-type samples, high $\mathrm{N}_{2}$ ratio of atmosphere can play a role in increasing the inhibitors, enhancing the ability of particle inhibition, and suppressing the coarsening of $\mathrm{MnS}$ that delayed the secondary recrystallization time. By contrast, for N-Type samples, the final annealing atmosphere can control the particle evolution behavior by influencing the coarsening of the nitride particles.

\subsection{Comparative analysis of particle Zener-pinning}

The pinning ability of inhibitors, which is usually used to determine the extent of particle ripening, plays a decisive role in the occurrence of secondary recrystallization. This ability determines the time and temperature of secondary recrystallization. Hence, pinning ability is an important parameter to measure the effect of inhibitors. In this paper, annealing time was processed as variable to analyze the relationship between pinning factor and secondary recrystallization. N-type samples did not undergo secondary recrystallization in this study. Thus, discussing the pinning ability of nitrides is not necessary. Only the pinning ability of $\mathrm{MnS}$ in S-type samples was analyzed in this paper. According to the theory of Zener relation ${ }^{32,33)}$, the particle pinning ability at different atmospheres and time can be estimated by a Zener factor $Z$, which can be simplified as follows:

$$
Z=\frac{3}{2} f_{v} / d
$$

where $f_{v}$ is the volume fraction of precipitates, and $d$ is the mean diameter of precipitates. The calculated results of S-type specimens are shown in Fig. 8.

According to eq (1), $\mathrm{Z}$ is directly proportional to $f_{v}$ but inversely proportional to $d$. Hence, higher number and finer particles will result in stronger pinning force. Theoretically, with prolonged soaking time, the gradual coarsening of particle will become dominant, the number of particles will decrease, and the average size will increase. These phenomena will lead to decreased particle Zener-pinning, which is consistent with the calculation results, as shown in Fig. 8. Thus, Fig. 2 and the above analysis shows that the sample processed under $50 \% \quad \mathrm{~N}_{2}+50 \% \mathrm{H}_{2}$ atmosphere started to undergo secondary recrystallization when the holding time was approximately $3 \mathrm{~h}$. Moreover, 221 may be the critical value of the Zener factor, below which the particles cannot effectively pin the grain boundaries, and secondary recrystallization will occur. During the whole heating preservation, the

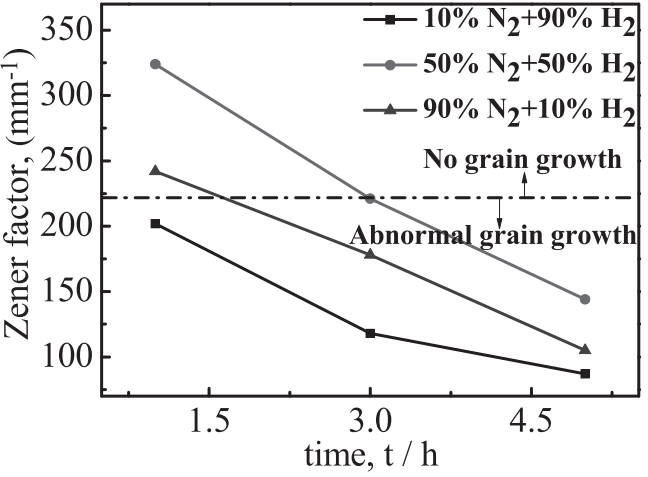

Fig. 8 Zener factor of precipitates of the S-Type samples in different atmospheres and at different soaking time.

value of Zener factor in the different atmospheres followed the rule $Z-50 \% \mathrm{~N}_{2}>Z-90 \% \mathrm{~N}_{2}>Z-10 \% \mathrm{~N}_{2}$. Secondary recrystallization occurred first because of the minimal Zener factor of $10 \% \mathrm{~N}_{2}+90 \% \mathrm{H}_{2}$ atmosphere. By contrast, under $50 \% \mathrm{~N}_{2}+50 \% \mathrm{H}_{2}$ atmosphere, increased nitride particles finally resulted in secondary recrystallization.

The final secondary recrystallization grains of S-type samples formed after annealing were mainly Goss or deviated Goss with reference to Fig. 2. Comparison and analysis of the pole figures of samples annealed under the three atmospheres showed that the deviated angle from the exact Goss orientation was minimal under the $50 \% \mathrm{~N}_{2}+50 \% \mathrm{H}_{2}$ atmosphere. Accordingly, an appropriate annealing atmosphere for $\mathrm{N}_{2} / \mathrm{H}_{2}$ ratios may exist, and some nitrogen can be infiltrated into S-type samples and promote the formation of nitride particles. This characteristic will enhance the inhibition ability, delay the onset time for secondary recrystallization, and form sharp Goss texture. The deviated Goss grains tended to grow abnormally when the $\mathrm{N}_{2}$ ratio in annealing atmosphere was too high or too low. For the 0.18-mm thick S-type samples fabricated in this paper, the relationship between final annealing atmosphere, holding time, and secondary recrystallization are expressed in Fig. 9. Nevertheless, annealing atmosphere of $50 \% \mathrm{~N}_{2}+50 \% \mathrm{H}_{2}$ is not necessarily the optimum atmosphere for the preparation of $0.18-\mathrm{mm}$ thick S-type specimens in this paper. Higher optimal annealing atmosphere ratio that makes sharper Goss texture may exist. Moreover, for $0.18-\mathrm{mm}$ thin-gauge plates of different compositions, the ideal secondary recrystallization with Goss texture may be obtained by optimizing the final annealing atmosphere.

Studies ${ }^{34-36)}$ have shown that when the secondary recrystallization occur near $1050^{\circ} \mathrm{C}$, a special orientation relationship between the Goss grains and the surrounding grains exists, which is high-angle grain boundaries. Moreover, Goss grains are less affected by particle pinning and tend to grow abnormally at low temperature prior to the deviated Goss grains ${ }^{11)}$. The difference in the orientation between Goss and deviated Goss texture is very small, and the threshold for suppressing abnormal Goss and deviated Goss grain growth and temperature range of rapid migration of grain boundaries might be very close. A study showed that the $\Sigma 9$ grain boundaries favorable to the abnormal growth of Goss grains had high mobility at approximately $975^{\circ} \mathrm{C}^{37)}$. Therefore, in 


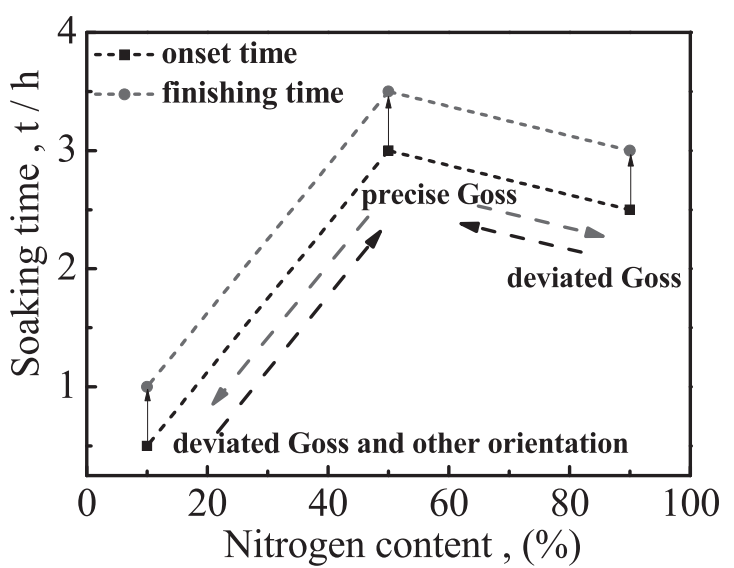

Fig. 9 The relationship between final annealing atmosphere, holding time and secondary recrystallization.

the temperature range close to $975^{\circ} \mathrm{C}$, the deviated Goss grains may also have high mobility and form a competitive relationship with abnormal growth of Goss grains. In this study, Fig. 8 shows the difference in the pinning capacities of inhibitors with extended soaking time at $950^{\circ} \mathrm{C}$ under different atmospheres. This phenomenon led to variations in the onset time between abnormal Goss and deviated Goss grain growth. According to Figs. 2 and 8, faster reduction in the pinning force to below the critical value will tend to the abnormal growth of more deviated Goss grains prior to Goss grains. This result is consistent with the simulation results of Fortunati and Abbruzzese ${ }^{38}$. By contrast, slow reduction in the pinning force results in longer inoculation time of Goss grains, leading to gradual increase in Goss grains and inhibiting the abnormal growth of deviated Goss grains. These conditions are conducive to improve the sharpness of Goss texture. Accordingly, the abnormal growth of Goss grains and deviated Goss grains may be greatly affected by annealing atmosphere. Thus, the grains have priority to grow abnormally depending on the specific annealing conditions.

The nitride inhibitors can be added by nitriding the thingauge oriented silicon steel with $\mathrm{MnS}$ as the main inhibitor and improve the formation environment of Goss texture.

\section{Conclusion}

In this study, final annealing experiments of two kinds of $0.18 \mathrm{~mm}$ thin-gauge cold-rolled grain-oriented silicon steel with $\mathrm{MnS}$ and $\mathrm{AlN}$ [mainly( $\mathrm{Al}, \mathrm{Si}) \mathrm{N}$ ] as primary inhibitors were performed. The ripening rate and state parameters of the two types of inhibitors under different annealing atmospheres were investigated. The following conclusions were drawn:

(1) The ripening temperature of MnS was lower than that of AlN particle. The particle gradually coarsened, and the number density of particles decreased with increased holding time under different atmospheric conditions. Higher proportion of $\mathrm{N}_{2}$ in the annealing atmosphere resulted in the more gradual ripening of the particle. Under $50 \% \mathrm{~N}_{2}+50 \% \mathrm{H}_{2}$ atmosphere, nitrogen could be infiltrated into the samples and form nitride inhibitors. This phenomenon enhanced the inhibition ability, which was stronger than those under the two other atmospheric conditions.

(2) For the $0.18 \mathrm{~mm}$ MnS-typed samples, faster decreasing rate of pinning force led to the increasing tendency of abnormal growth of deviated Goss grains prior to Goss grains. By contrast, longer inoculation time for Goss grains resulted in increased grain size for the Goss grains and inhibited abnormal growth of deviated Goss grains.

(3) For the $0.18 \mathrm{~mm}$ samples fabricated by the acquired inhibitor method, the coarse ( $\mathrm{Al}, \mathrm{Mn}, \mathrm{Si}) \mathrm{N}$ particles were the main products during the early stage, and the ripening rate under the different atmospheres was very slow when soaked at $950^{\circ} \mathrm{C}$. At $1000^{\circ} \mathrm{C}$, low proportion of $\mathrm{N}_{2}$ in the annealing atmosphere led to the rapid decomposition of (Al, $\mathrm{Mn}, \mathrm{Si}$ ) N particles, forming (Al, Si) N inhibitors. By contrast, the decomposition of (Al, Mn, Si) $\mathrm{N}$ particles and the coarsening of (Al, Si) $\mathrm{N}$ inhibitors were strongly inhibited and delayed with increased $\mathrm{N}_{2}$ content in the annealing atmosphere. Soaking at $950^{\circ} \mathrm{C}$ and $1000^{\circ} \mathrm{C}$ for $5 \mathrm{~h}$ showed no secondary recrystallization for the $\mathrm{N}$-type samples.

So far, numerous studies have been conducted on the thermodynamics and dynamics of $\mathrm{MnS}$ and $\mathrm{AlN}$ as inhibitors in silicon steel. These studies can be used as the basis to meet the needs of this paper. In this study, the coarsening behavior of $\mathrm{MnS}$ particles in plates fabricated by high-temperature hot-rolling method and the transformation of nitrides in plates fabricated by nitriding method are more complex because of the change in atmospheric factor. Therefore, in this paper, we mainly analyzed and discussed the annealing atmosphere and its effect on the evolution behavior of particles. The recrystallization behavior in thin-gauge plate was also investigated, and the annealing atmosphere suitable for preparing $0.18 \mathrm{~mm} \mathrm{MnS}$-typed sheets in three kinds of atmosphere was determined. Further calculations and discussions about the kinetics and thermodynamics will be performed in subsequent work.

\section{Acknowledgments}

This work is supported by National Key R\&D Program of China (Grant No. 2017YFB0903901, 2017YFB0903900) and China's State Grid Corporation of Science and Technology Projects(Grant No. SGRI-WD-71-13-002).

\section{REFERENCES}

1) S. Nakashima, K. Takashima and J. Harase: ISIJ Int. 31 (1991) 1013.

2) S. Nakashima, K. Takashima and J. Harase: J. Jpn. Inst. Metals 55 (1991) 898.

3) J.W. Flowers and S.P. Karas: J. Appl. Phys. 38 (1967) 1085.

4) W.M. Swift: Metall. Mater. Trans. B 4 (1973) 153.

5) W.P. Sun, M. MiliZer and J.J. Jonas: Metall Trans. 23A (1992) 821.

6) H.A. Wriedt: Metall. Trans. 10 (1980) 1731.

7) T. Sakai, M. Shiozaki and K. Takashina: J. Appl. Phys. 50 (1979) 2369.

8) J.H. Oh, S.H. Cho and J.J. Jonas: ISIJ Int. 41 (2001) 484

9) K. Iwayama and T. Haratani: J. Magn. Magn. Mater. 19 (1980) 15-17.

10) W.M. Mao, Z.G. An and Y. Li: Front. Mater. Sci. China 2 (2008) 233.

11) U. Yoshiyuki, K. Takeshi and T. Nobuyuki: ISIJ Int. 38 (1998) $553-558$.

12) J. Languillaume, G. Kapelski and B. Baudelet: Acta Mater. 45 (1997) 1201-1212.

13) Y. Ivanisenko, W. Lojkowski, R.Z. Valiev and H.J. Fecht: Acta Mater. 51 (2003) 5555. 
14) Y.J. Li, P. Choi, C. Borchers and S. Westerkamp: Acta Mater. 59 (2011) 3965-3977.

15) A.G. Mukoseev: Mater. Sci. Eng. A 316 (2001) 174

16) Y. Li, W. Mao and P. Yang: J. Mater. Sci. Technol. 27 (2011) 1120

17) H. Yashiki and T. Kukagawa: Mater. Trans., JIM 37 (1996) 503.

18) S. Nakashima, K. Takashima and J. Harase: ISIJ Int. 31 (1991) 1007-1012.

19) J. Harase, R. Shimizu and K. Takashima: Trans. ISIJ 27 (1987) 966.

20) T. Kumano, T. Haratani and N. Fujii: ISIJ Int. 45 (2005) 95.

21) S. Taguchi and A. Sakakura: Acta Metall. 14 (1966) 405.

22) S. Taguchi, A. Sakakura, F. Matsumoto, K. Takashima and K. Kuroki: J. Magn. Magn. Mater. 2 (1976) 121.

23) T. Takamiya, M. Kurosawa and M. Komatsubara: J. Magn. Magn. Mater. 254-255 (2003) 334.

24) Y. Ushigami, F. Kurosawa and H. Komatsu: US Patent. 5888314.

25) Y. Ushigami, F. Kurosawa, H. Masui, Y. Suga and N. Takahashi: Mater. Sci. Forum 204-206 (1996) 593.
26) J.S. Woo, C.H. Han, B.D. Hong and J. Harase: Acta Mater. 46 (1998) 4905.

27) C.H. Han and S.J. Kwon: Scr. Mater. 34 (1996) 543.

28) F.Y. Yang, C.X. He, L. Meng, G. Ma and W.M. Mao: J. Magn. Magn. Mater. 439 (2017) 403.

29) N. Takahashi and J. Harase: Mater. Sci. Forum 204-206 (1996) 143

30) C.C. Liao and C.K. Hou: J. Magn. Magn. Mater. 322 (2010) 434.

31) N.H. Heo and S.B. Kim: Metall. Mater. Trans. 37A (2006) 1689.

32) F.J. Humphreys: Acta Mater. 45 (1997) 5031.

33) H.X. Ma and Y.G. Li: Mater. Sci. Eng. 20 (2002) 328 (in Chinese).

34) Y. Hayakawa and J.A. Szpunar: Acta Mater. 45 (1997) 4713.

35) Y. Hayakawa and T. Omura: Mater. Trans. 54 (2013) 14.

36) Y. Hayakawa and J.A. Szpunar: Acta Mater. 45 (1997) 1285.

37) Y. Yoshitomi, Y. Ushigami, J. Harase, T. Nakayama, H. Masui and N. Takahashi: Acta Mater. 42 (1994) 2593.

38) S. Fortunati and G. Abbruzzese: Mater. Sci. Forum 204-206 (1996) 565 . 